\title{
VIDEOCONFERÊNCIA E HIPERVÍDEO COMO PROPOSTAS INTERATIVAS NA EDUCAÇÃO ONLINE: PENSANDO A FORMAÇÃO DE PROFESSORES PARA A EDUCAÇÃO CONTEMPORÂNEA
}

\author{
VIDEOCONFERENCE AND HYPERVIDEO AS INTERACTIVE PROPOSALS IN ONLINE EDUCATION: THINKING ABOUT \\ TEACHER TRAINING FOR CONTEMPORARY EDUCATION
}

VIDEOCONFERENCIA E HIPERVÍDEO COMO PROPUESTAS INTERACTIVAS EN EDUCACIÓN EN LÍNEA: PENSANDO EN LA FORMACIÓN DE PROFESORES PARA LA EDUCACIÓN CONTEMPORÂNEA

MARTINS, Vivian 1

SANTOS, Edméa ${ }^{2}$

\begin{abstract}
RESUMO
O artigo aborda o uso de audiovisuais na educação online a partir de uma prática pedagógica de produção de cibervídeos com estudantes da licenciatura em Pedagogia da Universidade do Estado do Rio de Janeiro. O objetivo da pesquisa foi compreender como os cibervídeos vêm se materializando e circulando no ciberespaço e, mais especificamente, na educação online, desenvolvendo, em contexto de pesquisa-formação na cibercultura, práticas de produção de gêneros de cibervídeos. O método escolhido foi a pesquisa-formação na cibercultura, onde as práticas de pesquisa e formação caminham em conjunto. A noção subsunçora Produção interativa de vídeos foi um dos achados da investigação, emergente das criações com hipervídeo e videoconferência pelas praticantes da pesquisa.
\end{abstract}

Palavras-chave: Cibervídeos. Educação Online. Videoconferência. Hipervídeo. Pesquisa-formação na cibercultura.

\section{ABSTRACT}

The article discusses the use of audiovisuals in online education from a cybervideo pedagogical practice production with undergraduate Pedagody students at Universidade do Estado do Rio de Janeiro. The aim of this research was to understand how cybervideos have been materializing and circulating in the cyberspace and, more specifically, at online education, developing, in the context of research-training in cyberculture and cibervideos genres production. The method chosen was research-training in cyberculture, both, together. We present one of the research findings, the conceived notion of interactive video production, with the hypervideo and videoconference that was created by the research professionals

Keywords: Cybervideos. Online education. Video conference. Hypervideo. Research training in cyberculture.

\section{RESUMEN}

El artículo aborda el uso de audiovisuales en la educación en línea desde una práctica pedagógica de producción de los cibervideos con estudiantes universitarios de pedagogía en la Universidade do Estato do Río de Janeiro. El objetivo de esta investigación fue comprender cómo los cibervideos se han materializado y circulado en el ciberespacio y, más específicamente, en la educación en línea, desarrollándose en el contexto de la investigación-formación en cibercultura, prácticas de producción del género de los cibervideos. El método elegido fue la investigación-formación en cibercultura, donde las prácticas de investigación y formación estan relacionadas. Presentamos uno de los resultados de la investigación, la noción concebida de producción de video interactivo, con el hipervídeo y la videoconferencia fueron creados por los profesionales de la investigación. Palabras clave: Cibervideo. Educacion en línea. Video conferencia. Hipervideo. Formación investigadora sobre cibercultura.

\footnotetext{
${ }^{1}$ Instituto Federal do Rio de Janeiro - IFRJ - Brasil.

2 Universidade Federal Rural do Rio de Janeiro - UFRRJ - Brasil.
} 


\section{PENSAMENTOS INTRODUTÓRIOS}

A cultura contemporânea mediada pelas tecnologias digitais em rede (SANTOS, 2014) move consideravelmente nossos usos e vivências. A educação online desponta como uma realidade e os vídeos possuem um papel de destaque nessas práticas. Interessados em compreender como os vídeos são apresentados na educação online, realizamos uma pesquisa de mestrado em educação (MARTINS, 2017), com o método da pesquisa-formação na cibercultura (SANTOS, 2014). Os cibervídeos, ou vídeos da cibercultura, são o grande tema da pesquisa e foram mapeados a partir do envolvimento das pesquisadoras na educação online.

No contexto da cibercultura, os vídeos digitais superaram em quantidade e qualidade os vídeos analógicos; questões como menor degradação temporal, facilidade de manipulação e edição proporcionam a disseminação dos vídeos e o estudo dos gêneros audiovisuais na cibercultura e, em especial, na educação online. O polo de emissão está liberado (LEMOS, 2002) e esses cibervídeos são semeados nas redes com a maior velocidade. As pessoas circulam com seus smartphones gravando cenas de todos os tipos, desde flagrantes até curiosidades.

O vídeo faz parte das misturas da cultura contemporânea, que proporcionam narrativas da cultura oral "intensificada pela sua integração nos meios audiovisuais" (SANTAELLA, 2007, p. 129), da cultura das mídias e da cibercultura. A cibercultura é multiplicidade, hibridismo, conexão, mobilidade e volatilidade, e apresenta mudanças significativas nas nossas formas de estar no mundo. A educação e a formação de professores, em especial, precisam considerar as mudanças sociotécnicas.

Para tanto, desenvolvemos uma pesquisa que buscava entrelaçar a investigação científica com os processos formativos na cibercultura. O método da pesquisa-formação na cibercultura atendeu a esse pressuposto, tendo em vista uma preocupação latente com a formação, principalmente a formação de professores. O objetivo da pesquisa foi compreender como os cibervídeos vêm se materializando e circulando no ciberespaço e, mais especificamente, na educação online, desenvolvendo, em contexto de pesquisa-formação na cibercultura, práticas de produção de gêneros de cibervídeos.

O contexto foi o da disciplina Tecnologias e Educação, da Licenciatura em Pedagogia da Universidade do Estado do Rio de Janeiro, onde acionamos o dispositivo de pesquisa denominado Oficina de produção de cibervídeos, possibilitando a produção de sentidos e de narrativas audiovisuais, imagéticas e textuais, contribuindo para a compreensão dos questionamentos que ampararam a pesquisa. Ao longo da pesquisa de mestrado encontramos sete gêneros de cibervídeos: hipervídeo, microvídeo, videoaula, videoconferência, vídeo instantâneo, vídeo volátil e webinar (MARTINS; SANTOS, 2019). Contudo, apresentaremos o hipervídeo e a videoconferência, que possuem relação direta com a noção subsunçora que pretendemos abordar no presente artigo.

Iniciamos o desenvolvimento do artigo com uma abordagem sobre os cibervídeos na educação online, apresentando o hipervídeo e a videoconferência como potências para a interatividade. Avançamos para o método de pesquisa utilizado ao longo da investigação, a pesquisa-formação na cibercultura. Em seguida desenvolvemos a noção subsunçora produção interativa de vídeos, 
decorrente do dispositivo de pesquisa Oficina de produção de cibervídeos. Encerramos com as considerações conclusivas, retomando os pontos abordados no texto. Encerramos com as considerações conclusivas, retomando os pontos abordados no texto.

\section{OS CIBERVÍDEOS DA EDUCAÇÃO ONLINE}

Os audiovisuais potencializam a produção de sentidos e significados. Eles possuem a capacidade de encantar e aflorar emoções profundas em quem os assiste. Se forem bem produzidos, proporcionam que a afetividade e a criatividade caminhem lado a lado aos processos educacionais. Por isso, podemos considerar que a educação é premiada com a sua presença, pois para a aprendizagem efetiva é preciso interesse e sensibilização. Com um tema sonoro e imagens, os vídeos podem exemplificar uma situação não imaginável ou disponível, a ilustração de conteúdos curriculares, a comunicação midiática como método de trabalho pedagógico e o desenvolvimento de habilidades cognitivas, relevantes para a prática pedagógica (MARTINS, 2017).

Babin e Kouloumdjianm (1989) descrevem as diferentes fases e os mecanismos do ato de compreender pelo audiovisual: choque audiovisual, estado emocional ambíguo, elaboração do sentido e a distância. Mais especificamente, o choque audiovisual é o efeito surpresa e de ruptura; o estado emocional ambíguo caracteriza-se pela confusão de sentir e não saber qual é a emoção; a elaboração do sentido ocorre quando aquele que recebe a mensagem audiovisual sai da confusão mental; e a última etapa, da distância, proporciona reflexão, conceitualização, apropriação e julgamento crítico do que se viu e sentiu.

Tais fases do audiovisual são didáticas e podem engrandecer a educação online. Com o choque audiovisual, é possível chamar a atenção do aluno para a temática, com sentimentos e emoções. Pode-se pensar na elaboração do sentido como associações e identificações de um conteúdo educacional, promovendo a aprendizagem significativa. Talvez nos faltem palavras para descrever uma situação, então o audiovisual contribui para o processo de compreensão de informações e de construção do conhecimento de forma crítica, que a etapa da distância propicia.

Diante de qualidades tão importantes para a educação encontradas nas fases de compreensão pelo audiovisual, estabelecemos os vídeos como objeto de estudo, em especial para os projetos de educação online. Em uma pesquisa exploratória selecionamos sete para aprofundamento (hipervídeo, microvídeo, videoaula, videoconferência, vídeo instantâneo, vídeo volátil e webinar) e desenvolvemos um dispositivo de pesquisa que proporcionasse a produção desses cibervídeos para propostas de construção de cursos online.

Dentre os sete tipos de cibervídeos trabalhados, consideramos o hipervídeo e a videoconferência os que possuem o maior potencial interativo. Pensando em uma educação dialógica e libertadora (FREIRE, 2013), é necessário trabalhar com interfaces que promovam a troca, a autoria, a autonomia, a construção colaborativa, a consciência crítica, a possibilidade de compartilhamento e da compreensão dos processos de subjetivação pelos quais os estudantes passam (MARTINS, 2019). Precisamos mudar a lógica da educação, de uma centralidade no conteúdo, para uma rede de 
conexões entre todos os envolvidos no processo, as propostas educacionais que incluem vídeos, mas não proporcionam a interatividade caem na perspectiva da transmissão de conteúdos. A educação online busca quebrar essa premissa, então os vídeos selecionados no presente artigo são os que viabilizam as ações mencionadas anteriormente em suas características originais. Sobre elas serão as próximas reflexões.

\title{
VIDEOCONFERÊNCIA
}

A videoconferência é um gênero de vídeo que possibilita, de maneira simultânea, explorar a imagem, o som e a linguagem corporal, podendo ser um dos cibervídeos que mais aproximam o online dos ambientes presenciais, pois passa a sensação de proximidade. É uma tecnologia que permite o contato visual e sonoro síncronos entre pessoas que estão geograficamente dispersas. Nesse sentido, Pesce, Hessel e Bruno (2010) concordam com Cruz (2010):

\begin{abstract}
Por trabalhar com interação em tempo real, conjugando som, imagem e movimento, a webconferência é uma das mídias que mais consegue aproximar-se da interação presencial, como em um chat audiovisual. (PESCE; HESSEL; BRUNO, 2010, p. 2).

A videoconferência é uma tecnologia que permite que pessoas ou grupos se comuniquem por imagem e som através de telas e microfones, dando a sensação de estarem todos num mesmo espaço físico. (CRUZ, 2010, p. 1).
\end{abstract}

Para um melhor entendimento, é importante sinalizar conceitualmente de onde falamos. A videoconferência é diferenciada de uma videoaula por ter característica sincrônica, por ensejar a interatividade, mas, para isso é fundamental ter criatividade e uma proposta pedagógica coerente, atenta e dialógica. Divirjo de Pesce, Hessel e Bruno (2010), para quem as videoconferências seriam "aulas geradas em estúdio e transmitidas pela televisão" (2010, p. 2) e as webconferências utilizariam a internet. Embora concordemos com as autoras em todos os outros posicionamentos expostos no referido artigo, destacamos videoaulas como aulas assíncronas e as videoconferências ou webconferências como interações síncronas.

Como a videoconferência possui características similares a uma atividade presencial, pode haver impulso para desenvolver uma dinâmica tradicional, com discurso monológico, em que o detentor do saber fala e os demais participantes "assistem". É interessante considerar a interatividade para um processo dialógico, para não tornar uma potência educacional em mais uma prática engessada.

Aprendizagem colaborativa, convergência de mídias, fluidez da oralidade e diminuição da sensação de distância entre docentes e alunos são relevantes para uma boa videoconferência. Okada (2008, p. 5) complementa: "[...] o uso de webconferência pode enriquecer comunidades virtuais. Isso significa tecnologia aplicada à reflexão abstrativa, contexto compartilhado, intermediação pedagógica múltipla e construção coletiva de conhecimentos". 
Os excertos em tela evidenciam algumas das características da webconferência. São elas: ampliação da perspectiva de alteridade; interlocução (direta ou mediada por outrem); interação; possibilidade de participar, a posteriori, da dinâmica de uma sala de aula; convergência das mídias; fortalecimento de vínculos. Tais características trazem ricas contribuições à aprendizagem em rede. (PESCE; HESSEL; BRUNO, 2010, p. 4).

As características da videoconferência são inúmeras, como já relacionadas por Pesce, Hessel e Bruno (2010). Dependendo de como é planejado, o cibervídeo pode ganhar lugar de destaque na formação online. Cruz (2010, p. 15) elenca algumas opções possíveis para trabalhá-la:

\begin{abstract}
Além dessas situações, os formatos de aulas mais comuns que se adequam à videoconferência e que podem ser feitas tanto separadamente como mescladas entre si, são as seguintes: a) aula inaugural, geralmente para apresentação da disciplina; b) aula de planejamento, muitas vezes para correção de rumo ou para coordenar alguma ação especial ou reuniões organizativas ou de trabalho entre alunos, entre professor e alunos ou entre tutores e alunos; c) realização de avaliação como exames ou provas; d) sessões de tira-dúvidas ou de revisão; e) apresentação de trabalhos ou seminários. (CRUZ, 2010, p. 15).
\end{abstract}

Como as aplicações da videoconferência serão de acordo com as condições de criação e inventividade, o cibervídeo pode ser explorado e apresentar propostas inovadoras. Por este motivo, é importante pensar na formação específica dos educadores para a docência no ciberespaço (SANTOS; MARTINS, 2018), pois a videoconferência não surtirá o efeito desejado caso os professores levem práticas antiquadas de mediação da aprendizagem.

Questões significativas, como o planejamento do processo educativo com antecedência, a roteirização do conteúdo e dos tempos para cada etapa, a humanização das ações, visando à maior aproximação e sensação de pertencimento entre os envolvidos, além do ambiente adequado (MARTINS; SANTOS; DUARTE, 2020) e conhecimento do cenário sociotécnico, precisam ser consideradas para não gerar uma subutilização dos recursos disponíveis.

Além de conhecer as características de maneira mais técnica e específica, o docente precisa fazer algumas ponderações: por ser uma interface síncrona, antes de decidir usar a videoconferência, o docente precisa considerar o seu público, o desenho didático da proposta, a disponibilidade dos envolvidos, os requisitos técnicos, como aparelhos que proporcionem uma videoconferência de qualidade (com imagem, som, enquadramento, iluminação, entre outros) e estabelecer regras de convivência.

Tab. 1 - Exemplos de videoconferências disponibilizadas no YouTube

\begin{tabular}{|l|l|l|}
\hline \multicolumn{2}{|c|}{ Exemplo } & \multicolumn{1}{|c|}{ Acesso } \\
\hline Vídeo da Colearn & & Profissionais da \\
Community intitulado & educação de \\
Educação Fora da & & diferentes locais \\
Caixa, & & conectados através do \\
\hline
\end{tabular}




\begin{tabular}{|c|c|c|}
\hline $\begin{array}{l}\text { videoconferência } \\
\text { liderada pela } \\
\text { professora Alexandra } \\
\text { Okada. }\end{array}$ & $\begin{array}{l}\text { https://www.youtube.com/watch?v=yKo20- } \\
\text { UZymA\&t=1828s }\end{array}$ & $\begin{array}{l}\text { Google Hangouts. } \\
\text { Seis interlocutores se } \\
\text { revezavam no uso da } \\
\text { palavra. Utilizaram a } \\
\text { captura de tela, } \\
\text { disponibilizaram vídeo } \\
\text { e arquivos. }\end{array}$ \\
\hline $\begin{array}{l}\text { Videoconferência } \\
\text { sobre Saberes da } \\
\text { Docência Online, com } \\
\text { apresentação da } \\
\text { professora Edméa } \\
\text { Santos no Open } \\
\text { University utilizando a } \\
\text { interface } \\
\text { Flashmeeting. }\end{array}$ & $\begin{array}{l}\text { http://fm.kmi.open.ac.uk/fm/fmmp.php?pwd=46d0ea- } \\
\text { 22023\&fb=0 }\end{array}$ & $\begin{array}{l}\text { A interface possibilita } \\
\text { a conversa em chat e } \\
\text { vídeo, mas no vídeo } \\
\text { somenter um } \\
\text { participante aparece } \\
\text { de cada vez. Há a } \\
\text { opção de } \\
\text { compartilhamento de } \\
\text { tela e indicadores } \\
\text { como tempo de fala de } \\
\text { cada integrante e } \\
\text { quais pessoas } \\
\text { acessaram a } \\
\text { videoconferência. }\end{array}$ \\
\hline
\end{tabular}

Fonte: elaborado pelas autoras (MARTINS, 2017).

A vivência das autoras do presente texto - como professoras que atuam no contexto digital e como pesquisadoras da área de educação online - tem apontado que a webconferência é um dos dispositivos de maior impacto sobre os processos de aprendizagem em rede. (PESCE; HESSEL; BRUNO, 2010, p. 1).

As autoras enaltecem a webconferência (entendida neste estudo como videoconferência, por motivos já expostos anteriormente) e destacam o potencial para a aprendizagem em rede. Pode-se dizer que é a aproximação mais fiel do presencial. Em tempos de cibercultura e educação em meio a uma pandemia (MARTINS; ALMEIDA, 2020), a videoconferência se destaca. Assim como o hipervídeo, que também apresenta uma proposta interativa como a videoconferência, mas com atributos próprios que serão estudados a seguir.

\section{HIPERVÍDEO}


O hipervídeo é um vídeo interativo que permite diálogo com o usuário, por meio de hiperligações internas ou externas ao vídeo principal. O vídeo pode apresentar, por exemplo: sites, apresentações, imagens, mapas conceituais, outros vídeos, zonas clicáveis diversas, widgets, perguntas de múltipla escolha ou discursivas. Bettencourt (2009) elenca algumas tipologias de hipervídeo, destacando suas características e singularidades:

- Hipervídeo detail on demand - A principal diferença para o hipervídeo tradicional consiste na presença de outros links ativos, que permitem uma utilização interativa com o usuário. "O utilizador pode requerer informação extra enquanto vê o vídeo em vez de ter de o fazer numa interface paralela", esclarece Bettencourt (2009, p. 14). A imagem a seguir pode ilustrar melhor o funcionamento dessa tipologia:

Fig. 1 - Exemplo de estrutura de um sistema de hipervídeo detail on demand.

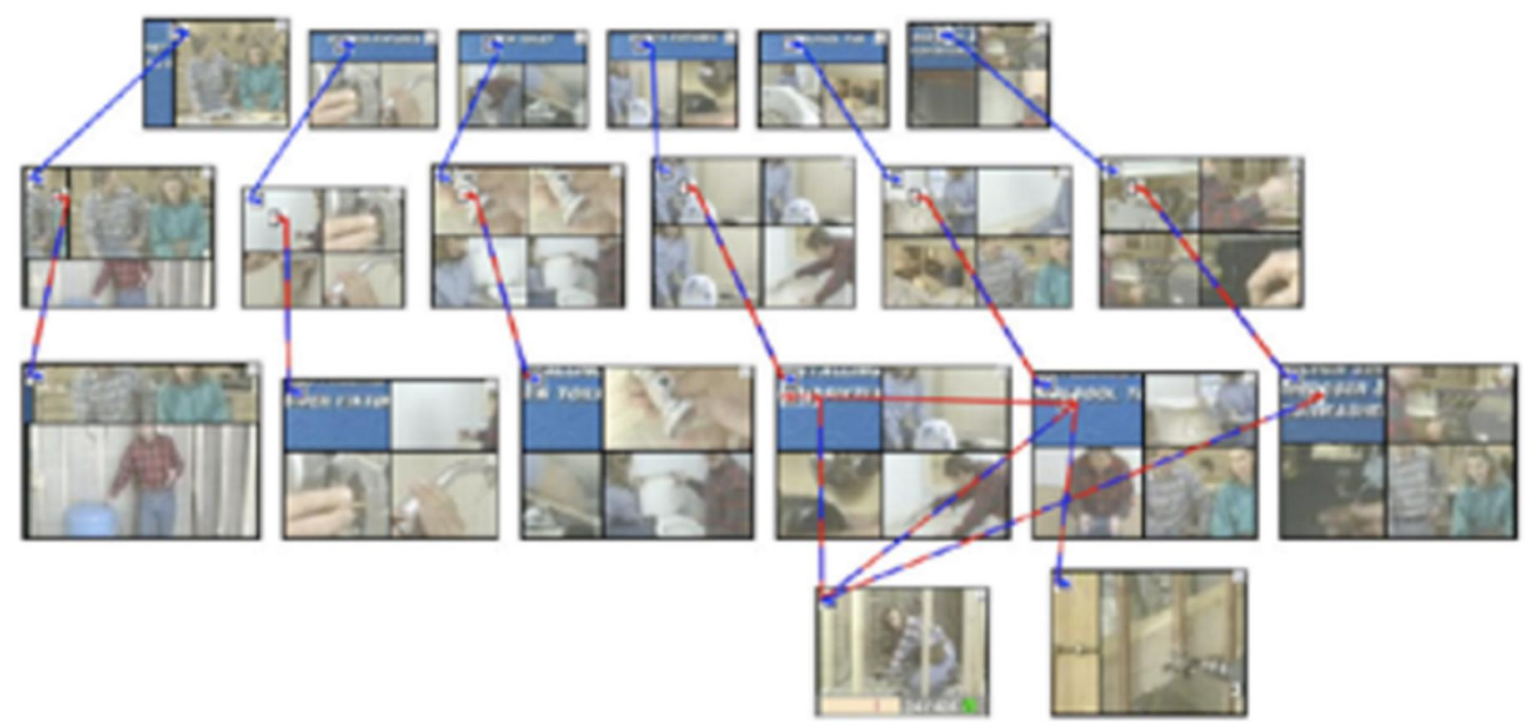

Fonte: Blum (1995, p. 167).

- Experiência de navegação - Prioriza a experiência de navegação do usuário, com uma rede de sequências que possibilita uma personalização da narrativa, com mudanças de enfoque, por exemplo.

Esta aplicação do hipervídeo, preocupada com a experiência do utilizador, faz mais sentido em narrativas interactivas do que propriamente em produções meramente descritivas. Em narrativas interactivas o utilizador procura caminhos e conta com que, a cada nova escolha nesse caminho, se vão abrindo, fechando, ou pelo menos filtrando, as suas hipóteses de diferentes desfechos. (BETTENCOURT, 2009, p. 15). 
- Estrutura linear com momentos fora dessa linearidade - O usuário pode alternar para outro link e retornar de onde parou. Por isso, o nome de linearidade/momentos fora dela. "A história tem um princípio e um fim, contudo, o seu desenvolvimento é marcado por momentos que podem ser de exploração para o utilizador", comenta Bettencourt (2009, p. 15).

- Estrutura Interconectada - "Esta trata-se duma estrutura com um princípio e um fim, que disponibiliza mais do que uma forma de ir dum ponto ao outro, o que se traduz geralmente em múltiplas perspectivas sob a mesma história." (BETTENCOURT, 2009, p. 16) Ou seja, o vídeo possui caminhos interconectados para chegar ao final e depende da escolha do usuário sobre qual percurso percorrer.

- Estrutura Adaptável - As histórias seguem paralelas e os segmentos conectados (mas não interconectados como a tipologia anterior). "O utilizador só tem acesso a toda a informação de que necessita se navegar para trás e para frente entre os diferentes segmentos", diz Bettencourt (2009, p. 16). É uma alternativa diferenciada das que já vimos anteriormente, com característica temporal ao navegar do fim para o início, se quiser possuir toda a informação disponibilizada no vídeo.

- Estrutura com um princípio e vários fins - Nesse caso, de acordo com Bettencourt (2009, p. 17), "partindo do início, o utilizador é depois induzido a tomar decisões em determinados momentos da história, que irão interferir na orientação da mesma". A pluralidade de caminhos e de finais é a característica dessa tipologia que talvez seja a proposta mais interativa de todas. A imagem a seguir foi retirada de Blum (1995, apud BETTENCOURT, 2009, p. 17) para exemplificar seu funcionamento:

Fig. 2 - Esquema da estrutura de um Hipervídeo na tipologia Princípio e vários fins 


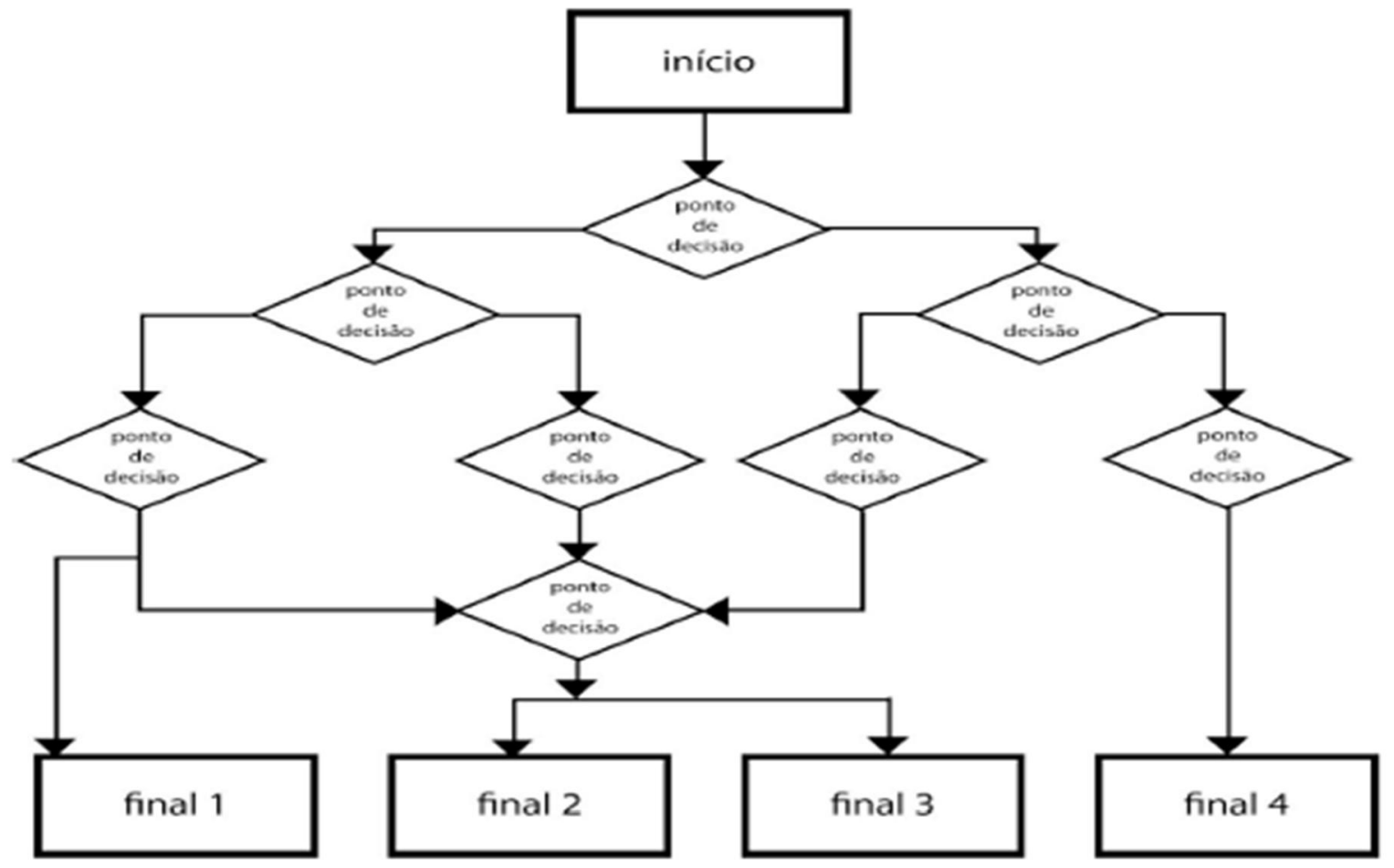

Fonte: Adaptado de Blum (1995, p. 167).

- Estrutura em Roda - "Esta estrutura não tem um ponto de partida num sentido tradicional. Existe um ponto, que serve como introdução, no entanto, é a partir deste que se decide qual o sentido a seguir (BLUM, 1995, p.170)" (BETTENCOURT, 2009, p. 17). Como exemplo, pode-se citar a navegação entre menus de DVD e entre capítulos.

Se desejar criar um hipervídeo, o educador pode recorrer, por exemplo, ao site Hapyak, para dotá-lo de mais funcionalidades como formulários, questões, botões, imagens, textos e ramificações, ou editá-lo no âmbito do YouTube, de forma mais superficial, incluindo direcionamento para vídeos, imagens, textos e hiperlink para qualquer conteúdo em rede, dependendo da necessidade ou interesse do idealizador. Todas as características já expostas conferem ao hipervídeo sentido de hipermídia e a qualificação de multimídia com elementos de hipertexto. Ainda é um cibervídeo pouco explorado na educação online, mas com enorme potencial, visto que compõe múltiplos recursos pedagógicos que favorecem os processos de ensino e aprendizagem.

Tab. 2 - Exemplos de hipervídeos disponibilizados no YouTube

\begin{tabular}{|c|c|c|}
\hline Exemplo & Acesso & Observação \\
\hline publicitário & & O vídeo apresenta \\
\hline denominado "What is & & possibilidades para criar \\
\hline Interactive Video?" do & & um hipervídeo através \\
\hline Hapyak, & & do site Hapyak, como a \\
\hline
\end{tabular}




\begin{tabular}{|c|c|c|}
\hline $\begin{array}{llr}\text { demonstrando } & \text { opções } \\
\text { para tornar } & \text { seu } & \text { vídeo } \\
\text { interativo } & \text { ou } & \text { um } \\
\text { hipervídeo. } & & \\
\text { hip. }\end{array}$ & https://www.youtube.com/watch?v=kqj_0506bFI & $\begin{array}{l}\text { inclusão de hiperlinks, } \\
\text { desenhos, questões e } \\
\text { legendas. }\end{array}$ \\
\hline $\begin{array}{l}\text { Vídeo denominado "Math } \\
\text { Video Quiz - Addition - } \\
\text { Educational - Interactive } \\
\text { for kids", de educação } \\
\text { matemática e destinado } \\
\text { ao público infantil. }\end{array}$ & https:/www.youtube.com/watch?v=mKA4-MA- & $\begin{array}{l}\text { O hipervídeo apresenta } \\
\text { perguntas e respostas } \\
\text { sobre adição. } \\
\text { hiperlink para outro } \\
\text { vídeo está na opção de } \\
\text { resposta: quando a } \\
\text { criança acerta é } \\
\text { direcionada para um } \\
\text { vídeo e quando erra } \\
\text { para outro. }\end{array}$ \\
\hline
\end{tabular}

Fonte: elaborado pelas autoras, 2017

Desmistificar a relação entre presença e ausência contribui para o uso da videoconferência, um cibervídeo que já é amplamente utilizado na educação online. Em contraponto, apresentamos o hipervídeo, não tão recorrente na educação online, mas que anuncia fatores consideráveis para a interatividade nos processos de ensino e aprendizagem, prometendo um grande impacto sobre a educação em rede. Após o estudo sobre os gêneros de cibervídeos, passaremos para a compreensão das bases metodológicas e epistemológicas da pesquisa.

\section{O MÉTODO DA PESQUISA-FORMAÇÃO NA CIBERCULTURA EM PANORÂMICA}

Na pesquisa-formação na cibercultura, há a proposta inicial de uma ambiência formativa que caminha entrelaçada com a pesquisa. Nesta experiência de investigação na cibercultura desenvolvemos dispositivos de pesquisa na educação online com os praticantes, deixando rastros na forma de narrativas textuais, imagéticas e audiovisuais. Rastros no atravessamento do ciberespaço, produzindo memórias formativas, momentos e acontecimentos relacionados com a plasticidade das tecnologias digitais. Os dados se materializam a partir das conversações, das práticas pedagógicas e das criações dos participantes. Eles são analisados para uma compreensão do fenômeno escolhido como objeto de estudo.

O contexto em que aconteceu a pesquisa foi a Universidade do Estado do Rio de Janeiro, as praticantes encontravam-se no primeiro período da licenciatura em Pedagogia, cursando a disciplina Tecnologias e Educação. Com idade entre 18 e 42 anos, possuíam alguns conhecimentos sobre os 
cibervídeos, pois são usuárias das diversas mídias sociais que proporcionam usos audiovisuais, mas não de forma sistematizada e direcionada para a educação online, como era o objetivo da pesquisa.

Os dispositivos de pesquisa são escolhas pedagógicas, políticas, éticas e metodológicas, acionadas pelo pesquisador para compreender os fenômenos da pesquisa. Como define Macedo, (2014, p. 43 e 44), o dispositivo é "[...] um artefato que é feito para alterar e ser alterado pela práxis dos atores envolvidos na experiência curricular, que pertence aos âmbitos, portanto, da alteração como emergência interativa humana". Implica processos formativos, produzindo ações e narrativas pelos praticantes envolvidos, expressando noções necessárias ao pesquisador para suscitar reflexões sobre os acontecimentos que perpassam a investigação. $O$ dispositivo da presente pesquisa recebeu o nome de Oficina de produção de cibervídeos.

Para a elaboração do dispositivo da pesquisa, houve um esforço de investigação sobre os fenômenos atuais da educação online. A recorrência da utilização do vídeo na composição dos desenhos didáticos o destacou como grande potência, podendo se configurar um interessante tema de pesquisa. Foi preciso teorizar sobre os vídeos e entender como eles estão sendo criados e disponibilizados na internet, para pensar em como utilizá-los em uma Pesquisa-formação. Compreender a cibercultura é fundamental para uma proposta de dispositivo coerente com os tempos atuais. Por isso, procuramos mapear os fenômenos audiovisuais que estão emergindo, em especial os que apresentam características educativas.

Durante a disciplina, utilizamos o ambiente virtual de aprendizagem no Moodle, um espaço formal, com o desenho didático estruturado; um grupo no Facebook, espaço para promover a conversação sobre conteúdos relacionados à disciplina, mediações e informações gerais; e alguns grupos no Whatsapp acionados pelos praticantes da pesquisa para desenvolver os trabalhos colaborativos, formados ao longo do dispositivo de pesquisa.

A Oficina foi desenvolvida no período de dois meses e a temática geral escolhida para a produção dos vídeos foi educar com a mídia, educar para a mídia e educar por meio da mídia (DUARTE, ELEÁ). Buscamos conhecer as características principais dos diferentes gêneros de cibervídeos; roteirizar, gravar e editar o recurso produzido através dos softwares indicados; divulgar o resultado do trabalho, por meio do Youtube e do grupo da disciplina no Facebook; e apresentar um relato de experiência sobre as implicações, as dificuldades e os êxitos obtidos na produção do audiovisual. Nesse último momento, gravamos a conversa sobre a realização do trabalho, possibilitando a análise posterior.

Durante o desenvolvimento do dispositivo de pesquisa os dados emergiram das criações dos praticantes e das experiências do pesquisador em campo. Noções subsunçoras são o esforço para interpretar o que emerge do campo, o que se constrói e se aprende a partir da pesquisa, o que vem da empiria e da sua formação prévia. São noções que emergem da conversa com os dados, com a prática e com suas vivências, elas representam o que ficou de significativo após a pesquisa, na relação igualitária entre prática, teoria e prática. Apresentamos a noção subsunçora a seguir.

\section{PRODUÇÃO INTERATIVA DE VÍDEOS}


A noção subsunçora produção interativa de vídeos perpassará pela autoria de vídeos que considerem a interatividade, refletindo sobre como é importante pensar em tal ponto para a elaboração de vídeos para a educação online. O encontro de pesquisa ocasionou uma multiplicidade de autorias, posicionamentos, argumentos e formas de fazer, na troca com o outro para ensinar e aprender a linguagem audiovisual.

A primeira leitura é sobre as praticantes do Grupo 3, que fizeram uma videoconferência com o tema Educar para a mídia. Apresentaremos o conteúdo dos vídeos de uma forma geral, para o caso do leitor não ter condições de assistir. O vídeo se inicia com a conceituação do tema, sobre como preparar os alunos para lidar com a sociedade de massa, com os diversos meios de disseminação, como a televisão, as mídias sociais, com olhar crítico, despertando a sensibilidade do educando. As participantes do vídeo comentam que, quando chega à sala de aula, a criança vem com uma bagagem cultural oriunda dos meios de comunicação, como a televisão, a internet, as revistas, entre outros. E acrescentam que os professores precisam estar atentos e se apropriar das mídias para tornar as aulas mais interessantes, trazer conteúdos em forma de debate para a sala de aula, proporcionando interação, reflexão e análise pelos alunos. Finalizaram o vídeo mostrando os bastidores da gravação, com todas as tentativas e os problemas de conectividade.

Fig. 3 - Captura da imagem da videoconferência sobre Educar para a mídia.

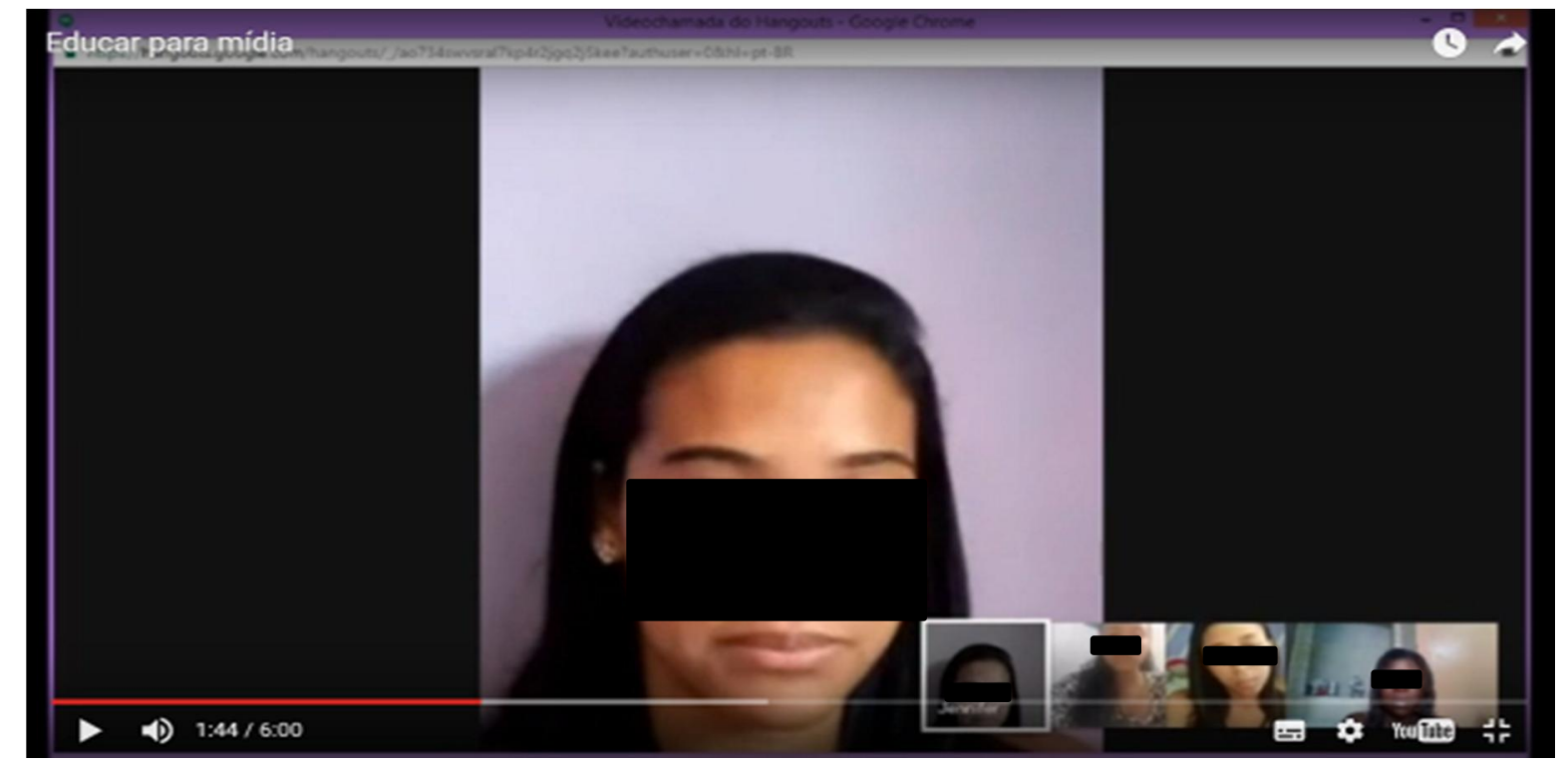

Fonte: https://www.YouTube.com/watch?v=yleZSd5yGpY

As praticantes do Grupo 3 passaram por dificuldades técnicas de conexão. De acordo com os relatos no momento da apresentação, precisaram realizar a videoconferência algumas vezes até a versão final. $O$ ideal seria que o restante da turma participasse e interagisse na videoconferência realizada pelo grupo, tendo em vista a forte característica de interatividade possível com o cibervídeo. Utilizo a palavra "possível" porque depende da vontade do mediador de percorrer tal caminho e das 
questões técnicas, como a interface e a conexão para que tenha maior quantidade de participantes. Tais fatores impossibilitaram a participação da turma completa na videoconferência.

O videoconferencista pode tanto franquear o diálogo para os demais participantes, como tornar o polo de emissão restrito. Como toda tecnologia, esta depende dos usos que dela são feitos. Como a videoconferência possui características similares às de uma atividade presencial, pode haver impulso para desenvolver uma dinâmica tradicional, com discurso monológico, em que o detentor do saber fala e os demais participantes "assistem". É interessante considerar a interatividade no processo, para não tornar uma potência educacional em mais uma prática engessada.

É necessário desenvolver uma atitude comunicacional não apenas atenta para as interações, mas que também as promova de modo criativo. Essa atitude supõe estratégias específicas desenvolvidas a partir da percepção crítica de uma mudança paradigmática em nosso tempo: a transição da tela da TV para a tela do computador ou a emergência de uma nova cultura das comunicações. (SANTOS; SILVA, 2014, p. 51).

Santos e Silva (2014) ressaltam os princípios para construir a sala de aula interativa: "provocar situações de inquietação criadora", "mobilizar a experiência do conhecimento", "propiciar oportunidades de múltiplas experimentações e expressões", "arquitetar colaborativamente percursos hipertextuais" e "disponibilizar uma montagem de conexões em rede que permita múltiplas ocorrências" (p. 55 e 56). Nos princípios acima, destacam-se noções importantes para pensar uma sala de aula interativa. Buscamos considerar tais pressupostos na elaboração e no desenvolvimento da Oficina de produção de cibervídeos, com as experimentações, as autorias de cibervídeos potentes para a educação online e a disponibilização em rede.

Nesse sentido, emerge o Hipervídeo do grupo 6, denominado "Vídeos na Cibercultura". As praticantes utilizaram uma abordagem cinematográfica e simularam o encontro de duas alunas para um trabalho em grupo. Ao longo do vídeo, demonstraram características da cibercultura, como o uso das mídias sociais, de tablets e de aplicativos de mensagens instantâneas. As conversas entre as personagens estão relacionadas ao audiovisual na educação, com dicas de livros e filmes clássicos. 0 vídeo discorre ainda sobre a história do cinema e sobre o conceito de hipervídeo, já que em cena, as personagens resolveram gravar um hipervídeo para um trabalho em grupo.

Links são incluídos no vídeo com a possibilidade de saber mais sobre os assuntos falados pelas personagens. A captura da imagem do hipervídeo, na figura 5, foi realizada no momento em que um hiperlink foi disponibilizado. As personagens citam um livro e recomendam a sua leitura, disponibilizando o link para conhecer o material, um hipervídeo detail on demand (BETTENCOURT, 2009).

Fig. 4 - Captura da imagem do hipervídeo sobre Vídeos na Cibercultura. 


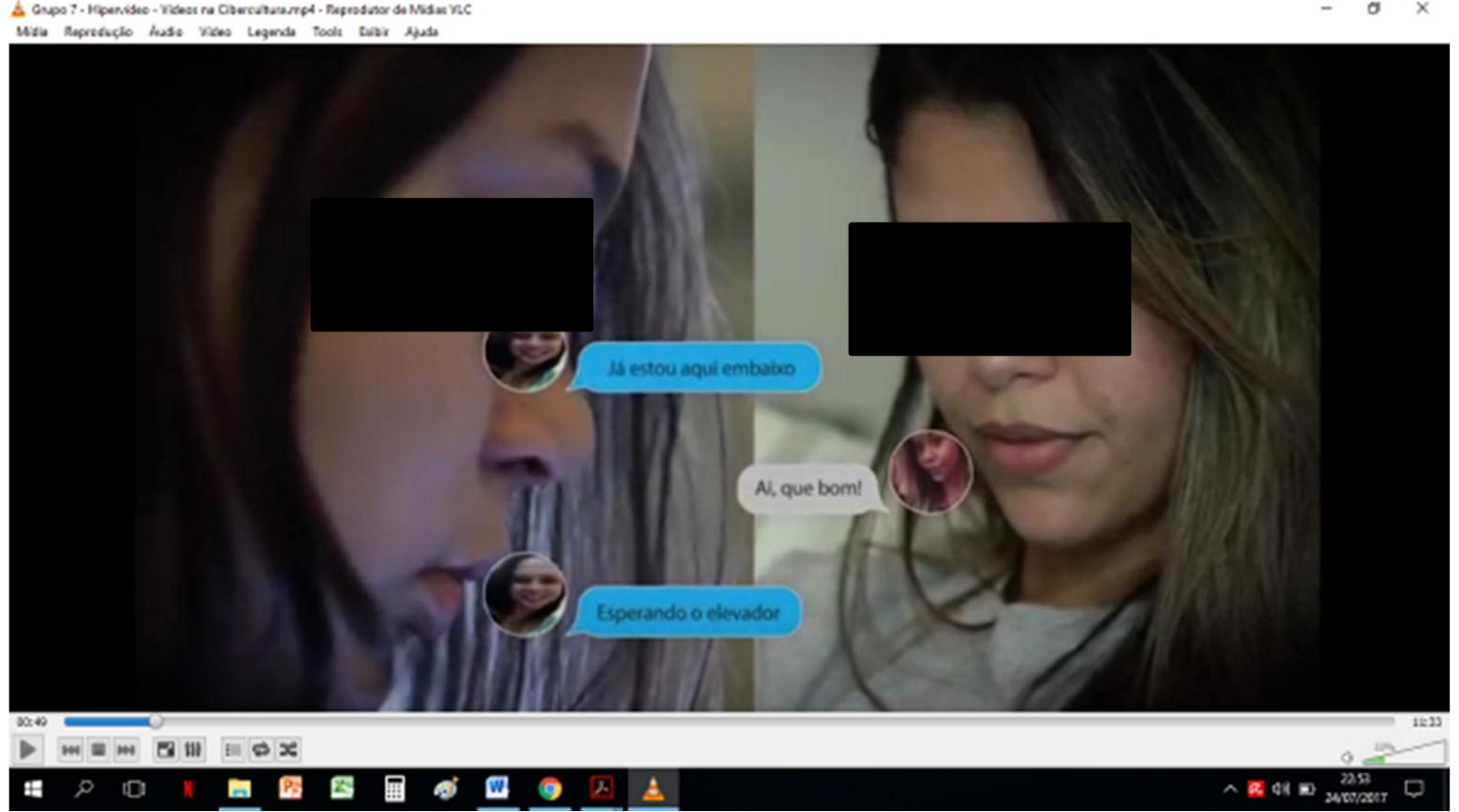

Fonte: https://www.YouTube.com/watch?v=sU2USSbr91s\&feature=youtu.be

Fig. 5 - Captura da imagem do hipervídeo sobre Vídeos na Cibercultura.

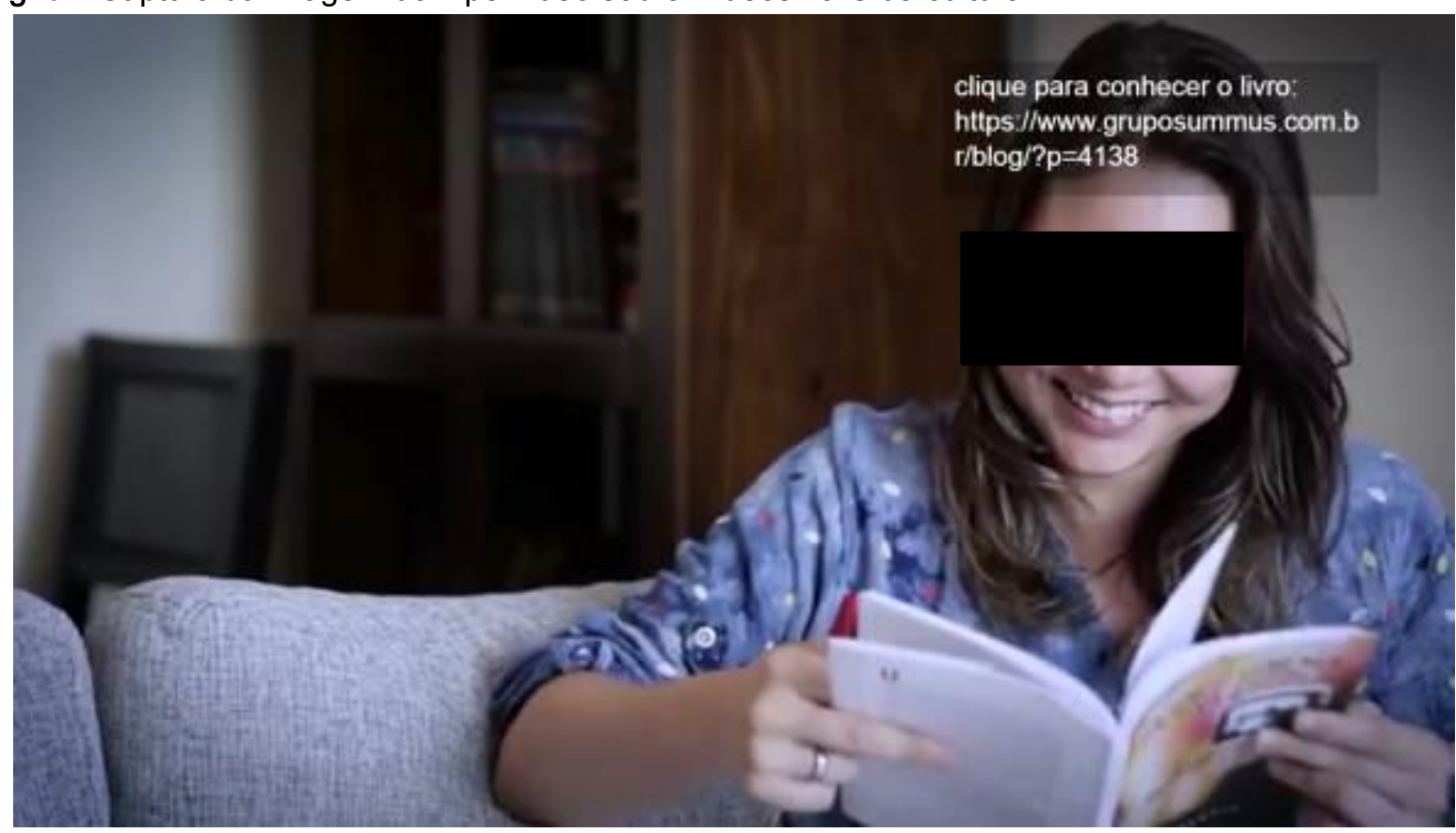

Fonte: $w w w$. YouTube.com/watch?v=sU2USSbr91s\&feature=youtu.be

Não poderíamos deixar de destacar o hipervídeo ao falar sobre interatividade na produção audiovisual. Todos os grupos apresentaram autorias singulares, atuações e participações importantes, entretanto, o hipervídeo apresenta possibilidades técnicas que promovem uma interatividade inerente às suas características originais, como: hipervídeo detail on demand (BETTENCOURT, 2009), onde o usuário interage clicando nos links ativos pra acessar informação extra; rede de sequências que 
possibilita uma personalização da narrativa, a interatividade ocorre na opção do usuário pelos caminhos que o vídeo seguirá; estrutura linear com possibilidades de intercalar em outros pontos do vídeo, interagindo pela exploração do usuário; estrutura interconectada, com múltiplas perspectivas sob a mesma história, a escolha do espectador; estrutura adaptável, com as histórias paralelas ao vídeo original e seus segmentos conectados, não mostrando uma história única; estrutura com um princípio e vários fins, onde as decisões dos usuários interferem na conclusão da história; e estrutura em roda, onde só o ponto de partida é estático, o restante fica a critério do usuário, demandando bastante interferência e interatividade.

De forma a exemplificar as características do hipervídeo, apresentamos o episódio Bandersnatch da série Black Mirror, disponível no Netflix (MARTINS; SANTOS, 2020). A trama é passada em 1984 e retrata a história de um desenvolvedor que opta por transformar um livro interativo em um jogo, ao apresentar a ideia para uma empresa de jogos é contratado para desenvolver em um curto período de tempo. Também chamado de jogo interativo, nós espectadores realizamos opções sobre o desenvolvimento da história, há escolhas ao longo de todo o episódio, desde as escolhas mais singelas que pensamos não influenciar diretamente a trama principal até escolhas que repercutem diretamente na morte ou vida dos personagens. O episódio possui um final com no mínimo 5 conclusões diferentes, de acordo com a Netflix, mas alguns espectadores conseguiram encontrar 10 conclusões ou desfechos secretos.

No episódio Bandersnatch pode-se encontrar experiência de navegação, estrutura interconectada, adaptável, com um princípio e vários fins. O roteiro "permite que os mais criativos construam narrativas complexas que incluem loops, guiando os espectadores de volta à história principal quando eles se afastaram demais do roteiro, dando a eles uma chance de fazer tudo de novo" (COSSETTI, 2019). Dependendo das escolhas do usuário, a experiência pode ser finalizada em 40 minutos, 90 minutos ou em cinco horas, com a experiência completa com todos os vídeos gravados, quando o espectador estiver à procura dos 10 finais. Em um desses finais, a trama se desenvolve com o personagem principal percebendo que está sendo controlado por alguém, uma interação da trama com a nossa existência enquanto interlocutores.

Bandersnatch proporciona uma experiência diferente da habitual, de assistir como espectadores ao conteúdo audiovisual. O episódio provoca uma sensação de responsabilidade com a trama, pertencimento com o resultado, é imersivo e interativo. Optamos por trazer esse caso para ilustrar as inúmeras possibilidades de uma produção interativa de vídeos. O conteúdo educacional não precisa estar distante da realidade e dos formatos apresentados pelos estudos da comunicação. As particularidades do episódio de Black Mirror podem ser pensadas para proporcionar reações e sensações similares ao assistir a uma aula.

Percebendo a possibilidade de mixagem dos gêneros, pode-se entender que as características do hipervídeo podem ser incluídas em diversos formatos de produção audiovisual, como uma videoaula, com um toque cibercultural, que não apresenta as características lineares no formato de preleção. A intenção que ampara essa pesquisa-formação na cibercultura é a produção de audiovisualidades pelos praticantes, levando a ações como: mesclar, bricolar, inventar, produzir, 
ressignificar (AMARO; SOARES, 2016) para o horizonte vasto de possibilidades profissionais futuras desses praticantes.

Destacamos a narrativa de Karen Rodrigues sobre a produção audiovisual. Karen participava do Grupo 6, que desenvolveu o hipervídeo. A narrativa emergiu de uma conversa após a apresentação dos trabalhos produzidos pelos grupos. Quando questionada sobre quais saberes a mobilizaram para a construção do trabalho e o que seria levado daquela oficina, ela respondeu:

\footnotetext{
Karen Rodrigues: Acho que para o meu primeiro semestre, esse trabalho vai ser o que eu vou levar assim como lembrança realmente. Para além do gênero hipervídeo, que agora eu aprendi, porque eu não conhecia. Na verdade, eu via as vezes na internet, mas não via a fundo. $E$ essa coisa de se conectar com as outras coisas que a pessoa está falando do vídeo, conseguir ver e conhecer o que a pessoa leu. Mas, além disso, com certeza, a participação, a filmagem, a edição, isso foi espetacular.
}

A interatividade entre os praticantes foi fundamental para uma aprendizagem significativa, em uma proposta que se caracteriza por uma educação todos-todos. Interessante ressaltar a emoção que a praticante reflete sobre as vivências ao longo da construção colaborativa do audiovisual. Destaco a palavra "experiência" na narrativa de Karen como algo similar ao sentido da palavra para Larrosa (2002). O autor evidencia que a tendência é usar experiência como sinônimo de informação, conhecimento e aprendizagem, quando, na verdade, o saber da experiência é "o que se adquire no modo como alguém vai respondendo ao que vai the acontecendo ao longo da vida e no modo como vamos dando sentido ao acontecer do que nos acontece" (LARROSA, 2002, p. 27). Quando Karen disse que iria "levar assim como lembrança realmente", imaginamos que essa tenha sido uma narrativa de experiência e que, caso a praticante não tivesse mencionado o que a tocou e o que a atravessou, nós não poderíamos dizer que as experiências aconteceram por considerarmos a pessoalidade do fenômeno.

Freire (2013) afirma que o conjunto do saber se encontra em interação e na dialogicidade. A comunicação ganha um espaço de destaque na "teoria do conhecimento" (FREIRE; GUIMARÃES, 2013), desenvolvida por Freire, que entendia que a educação era dialógica e que era a partir da troca que os saberes eram construídos, em conjunto. Educação é comunicação e não transferência de conhecimento em um processo unilateral, como os preceitos da Pedagogia Tradicional supõem. Freire (2013) menciona a palavra "encontro" ao designar educação, um encontro entre sujeitos em processos de significação subjetivos e complexos. O autor nos faz refletir sobre propostas cada vez mais dialógicas em nossas práticas e elencamos a videoconferência e o hipervídeo unidos com propostas pedagógicas autorais, reflexivas, colaborativas e que possibilitem a comunicação bidirecional como possibilidades para a interatividade na educação online.

\section{CONSIDERAÇÕES FINAIS}


Os vídeos ganham destaque na educação contemporânea e possuem características que aproximam pessoas em propostas não presenciais. Como forma de não priorizar somente o conteúdo nos processos educativos, buscamos propostas audiovisuais que contassem com a interatividade para que uma educação dialógica fosse idealizada, abrindo a possibilidade de intervenção dos estudantes (tanto em áudio e vídeo, como na videoconferência, quanto em cliques e intervenções, como no hipervídeo). Partindo do pressuposto de que a educação precisa partir da construção conjunta e não necessariamente da transmissão unidirecional de saberes.

Iniciamos o estudo com a apresentação de dois cibervídeos utilizados na educação online: videoconferência e hipervídeo. Escolhemos os dois, pois a produção deles pelos praticantes da pesquisa e as múltiplas narrativas decorrentes dessa experiência contribuíram para a construção de noções importantes para a pesquisa. Nesse tópico abordamos as especificidades comunicacionais, pedagógicas e técnicas de cada gênero, trazendo exemplos de vídeos disponibilizados no YouTube.

$\mathrm{Na}$ sequência, apresentamos a Pesquisa-formação na cibercultura, o método de pesquisa escolhido para o delineamento da investigação que se pretendia realizar, com a formação de professores na educação superior. Apresentamos o dispositivo de pesquisa Oficina de produção de cibervídeos, de onde emergiram narrativas textuais, imagéticas e audiovisuais. Foi nesse movimento da pesquisa-formação que emergiram as noções subsunçoras, a partir de uma triangulação entre as questões de pesquisa, narrativas emergentes do campo e o referencial bibliográfico que ampara a dialogia entre prática, teoria e prática.

Por fim, apresentamos a noção subsunçora produção interativa de vídeos, considerando a interatividade no processo de elaboração e de desenvolvimento dos vídeos, refletindo sobre "o compartilhamento, a conectividade, a interlocução, a colaboração e a liberação da autoria" (SILVA, 2012, p. 7) como potencialidades para a criação de vídeos interativos. Apresentamos os vídeos produzidos pelas praticantes da pesquisa e exemplificamos com o caso do hipervídeo produzido para a série Black Mirror, como uma realidade que pode ser pensada para a educação contemporânea.

Concluímos reforçando a necessidade de refletirmos sobre as práticas realizadas nos processos de ensino e aprendizagem hoje. A proposta de produção de vídeos interativos busca inspirar educadores a incluírem essa possibilidade em suas práticas pedagógicas. Nossa concepção de educação e audiovisual prevê criatividade, autoria e interatividade, necessárias para uma educação democrática e dialógica. Ao designar educação a partir da palavra encontro, Freire nos inspira a refletir sobre práticas cada vez mais dialógicas e interativas, que esse encontro e os nossos pensamentos motivem aos leitores desse artigo a criar e recriar em seus cotidianos.

\section{REFERÊNCIAS}

1. AMARO, Ivan; SOARES, Maria da Conceição Silva (orgs.). Tecnologias digitais nas escolas: outras possibilidades para o conhecimento. 1. ed. Petrópolis, RJ: DP et Ali, 2016.

2. BABIN, Pierre; KOULOUMDJIAN, Marie-France. Os novos modos de compreender: a geração do audiovisual e do computador. Tradução Maria Cecília Oliveira Marques. São Paulo: Paulinas, 1989. 
3. BETTENCOURT, Carolina. O hipervídeo aplicado à cibermuseologia. 132 f. Dissertação (Mestrado). Departamento de Comunicação e Arte. Universidade de Aveiro, 2009.

4. BLUM, B. Interactive Media - Essentials for Success. Califórnia, EUA: Ziff-Davis Press, 1995.

5. CRUZ, Dulce Maria. A potencialidade educacional e dialógica da videoconferência na EAD. In: SILVA, Marco; PESCE, Lucila; ZUIN, Antônio (orgs.). Educação online. Rio de Janeiro: Wak Editora, 2010, v. 1, p. 279-308.

6. DUARTE, Rosália; ELEÁ, lleana. Mídia-educação: teoria e prática. In: SANTOS, Edméa. (org.). Mídias e tecnologias na educação presencial e a distância. Rio de Janeiro: LTC, 2016, p. 3-17.

7. LARROSA, Jorge. Notas sobre a experiência e o saber da experiência. Revista Brasileira de Educação. Rio de Janeiro, N. 19, p. 20-28, 2002. Disponível em: www.scielo.br/pdf/rbedu/n19/n19a02.pdf. Acesso em: 19 jul. 2017.

8. LEMOS, André. Cibercultura: Tecnologia e vida social na cultura contemporânea. Porto Alegre: Sulina; Meridional, 2002.

9. MACEDO, Roberto S. Atos de currículo, formação em ato?: para compreender, entretecer e problematizar currículo e formação. 2. reimpressão. Ilhéus: EDITUS, 2014. 170 p.

10. MARTINS, Vivian. Os cibervídeos na educação online: uma pesquisa-formação na cibercultura. 178 f. Dissertação (Mestrado em Educação) - Faculdade de Educação, Universidade do Estado do Rio de Janeiro, Rio de Janeiro, 2017. A Educação online e a formação para a videodocência na cibercultura. Revista Educação (UNISINOS), v. 23, p. 390-407, 2019.

12. MARTINS, Vivian; ALMEIDA, Joelma F. F. Educação em tempos de pandemia no Brasil: saberesfazeres escolares em exposição nas redes. Revista Docência e Cibercultura, v. 4, p. 215224, 2020.

13. MARTINS, Vivian; SANTOS, Edméa. A produção de cibervídeos na formação de professores: reflexões para a educação on-line. Revista EmRede - Revista de Educação a Distância, v. 6, p. 221-233, 2019.

14. _ _ Black Mirror, internet das mentes e educação: como migraremos da cultura do efêmero para as super memórias da cerebralidade artificial? Revista Communitas, v. 4, p. 139-157, 2020. 
15. MARTINS, Vivian; SANTOS, Edméa; DUARTE, Érika F. A educação online e os desenhos didáticos com interfaces móveis: autorias em ambientes virtuais de aprendizagem web e aplicativos. Revista Debates em educação, v. 12, p. 785-804, 2020.

16. OKADA, Alexandra. Aprendizagem aberta e estratégias de webconferência. Revista CoLearn. Projeto OpenLearn The Open University UK. Vol., 1, n. 1, p. 1-6, Nov. 2008. Disponível em: http://labspace.open.ac.uk/journal. Acesso em: 06 ago. 2017.

17. PESCE, Lucila; HESSEL, Ana; BRUNO, Adriana Rocha. Experiências com webconferência: a constituição de comunidades de aprendizagem. Trabalho apresentado no Séptimo Simposium Iberoamericano en Educación, Cibernética e Informática: SIECI. Orlando, 2010.

SANTAELLA, Lucia. Linguagens líquidas na era da mobilidade. 2 ed. São Paulo: Paulus, 2007.

SANTOS, Edméa O. Pesquisa-formação na cibercultura. 1. ed. Santo Tirso: Whitebooks, 2014. V. 1. $202 p$.

SANTOS, Edméa; MARTINS, Vivian. Cibervideos e multiletramentos na educação online. Revista Observatório, v. 4, p. 231-262, 2018.

21. SANTOS, Edméa O.; SILVA, Marco. A pedagogia da transmissão e a sala de aula interativa. Coleção Agrinho. Paraná, 2014. Disponível em: www.agrinho. com.br/site/wpcontent/uploads/2014/09/2_02_A-pedagogia-da-transmissao.pdf Acesso em: 24 jul. 2017.

22. SILVA, Marco. "Vivemos em um cenário midiático muito favorável à educação cidadã”. Entrevista a Carla Viana Coscareli e Ana Elisa Ribeiro. Presença Pedagógica. Belo Horizonte, v. 18, n. 106, p.01-11, jul./ago. 2012.

\section{Vivian Martins}

Doutoranda do Programa de Pós-graduação em Educação da Universidade do Estado do Rio de Janeiro (UERJ). Possui mestrado em Educação pela UERJ, especialização em Planejamento, Implementação e Gestão da Educação a Distância pela Universidade Federal Fluminense (UFF), MBA em Gestão de Recursos Humanos pela UFF, Licenciatura e Bacharelado em Pedagogia pela UERJ. Professora de Educação a Distância e Tecnologias Educacionais do Instituto Federal de Educação, Ciência e Tecnologia do Rio de Janeiro (IFRJ). Membro do Grupo de Pesquisa Docência e Cibercultura (GPDOC-UERJ) e do grupo Literacia visual: pesquisa, ensino e formação docente em Artes (IFRJ). Tem experiência na área de Educação, com ênfase em educação e cibercultura, pesquisa e prática 
pedagógica, formação de professores, educação online e tecnologias educacionais. Site: http://docenciaonline.pro.br/moodle/course/view.php?id=87 E-mail: vivian.martinst@gmail.com.

\section{Edméa Santos}

Professora Titular-Livre da Universidade Federal Rural do Rio de Janeiro (UFRRJ). Atua no Instituto de Educação e no Programa de Pós-Graduação em Educação (PPGEDUC), na linha de pesquisa " Linha 1: Estudos Contemporâneos e Práticas Educativas". Durante o período de 2007 a 2018, foi professora Adjunta da Faculdade de Educação da Universidade do Estado do Rio de Janeiro (UERJ), atuando na Graduação e no Programa de Pós-Graduação em Educação (PROPED/UERJ) (onde colabora, junto à linha de pesquisa "Cotidianos, redes educativas e processos culturais"). Professora da disciplina Informática na Educação no curso de Pedagogia a Distância UERJ/CEDERJ. Editora-chefe da Revista Docência e Cibercultura. Pedagoga pela UCSAL, mestre e doutora em Educação pela UFBA. Pósdoutora em e-learning e EAD pela UAB-PT, onde colabora esporadicamente no MPEL - Mestrado em Pedagogia do e-Learning . Líder do GPDOC - Grupo de Pesquisa Docência e Cibercultura. Membro do Laboratório de Imagem da UERJ. Atua na formação inicial e continuada de professores e pesquisadores. Áreas de atuação: "Educação e Cibercultura, Pesquisa e Práticas Pedagógicas, Formação de Professores, Currículos: teorias, práticas e políticas, Informática na Educação, Educação Online e EAD". Site: http://edmeasantos.pro.br E-mail: edmeabaiana@gmail.com.

\section{Como citar este documento:}

MARTINS, Vivian; SANTOS, Edméa. Videoconferência e hipervídeo como propostas interativas na educação online: pensando a formação de professores para a educação contemporânea. Reflexão e Ação, Santa Cruz do Sul, v. 28, n. 3, p. 113-132, ago. 2020. ISSN 1982-9949. Disponível em: <https://online.unisc.br/seer/index.php/reflex/article/view/14316>. Acesso em: doi:https://doi.org/10.17058/rea.v28i3.14316. 